\title{
Aprendizagem Colaborativa Mediada pelo Squeak
}

\author{
Cícero Bandeira Lima Filho ${ }^{1}$, José Aires de Castro Filho ${ }^{2}$ \\ ${ }^{1}$ Secretaria Municipal da Educação de Quixadá \\ ${ }^{2}$ Instituto UFC Virtual - Universidade Federal do Ceará (UFC) \\ cicerobandeira@yahoo.com.br, aires@virtual.ufc.br
}

\begin{abstract}
Resumo: o presente trabalho analisa as contribuições das tecnologias digitais aos processos de ensino e aprendizagem. A abordagem adotada baseia-se na aprendizagem colaborativa e a ferramenta digital escolhida teve por objetivo dar suporte ao estudo dos conteúdos escolares, numa perspectiva problematizadora. No decorrer da intervenção, os participantes produziram desenhos e animações para representar conteúdos de Biologia do Ensino Médio, utilizando o aplicativo Squeak. As análises realizadas permitiram identificar que as diversas interações que surgiram entre os pares de alunos e o professor possibilitaram maior envolvimento com os conteúdos, trocas de ideias e formulação de novos entendimentos.
\end{abstract}

\begin{abstract}
: the present work analyzes the digital technologies contributions to the teaching and learning processes. The approach is based in a collaborative learning and the digital tool selected aimed to support to study of school subjects, in a problematical perspective. During the intervention, the participants produced drawings and animations to represent the High School Biology content, using the Squeak application. The analyzes carried allow identify that several interactions that arisen between pairs of students and the teacher that allowed greater involvement with contents, exchange of ideas and new understandings formulation.
\end{abstract}

\section{Introdução}

A presença das tecnologias digitais no cotidiano escolar tem sido objeto de variados estudos. Autores como Papert (2008), Kenski (2007), Berens (2007) e Cool (2010), dentre outros, discutem o potencial educacional desses instrumentos e compartilham da ideia que apenas a presença de equipamentos tecnológicos em sala não é suficiente para otimizar os processos de ensino e de aprendizagem.

Para ter acesso aos benefícios proporcionados pelas tecnologias digitais é necessário romper com os modelos de educação que se consolidaram ao longo da nossa história educacional e têm como foco a passividade dos alunos e uma perspectiva individualista do processo de aprender.

O fazer pedagógico nas escolas brasileiras ainda tem como característica a predominância da "didática da transmissão", da "pedagogia do discurso", da 
"transmissão desprovida de contexto" (BRASIL, 2002, p.11) O professor ainda ocupa um lugar muito central, colocando os alunos numa posição de passividade (SAVIANI, 2010). Proporcionar uma experiência que altere este modelo é uma tarefa desafiadora.

A perspectiva apresentada neste trabalho baseia-se nos fundamentos da Aprendizagem Colaborativa com Suporte Computacional (CSCL), discutida por Sthal, Koschmann e Suthers (2006). De acordo com a CSCL para realizar formas de aprendizado mais enriquecedoras será necessário utilizar os instrumentos a partir de abordagens que promovam ações colaborativas entre os participantes, momentos de trocas, de envolvimento e compartilhamento. Neste sentido o computador servirá como suporte que possibilitará construção de soluções a problemas específicos de cada área do saber.

A CSCL prevê a utilização de recursos tecnológicos para dar suporte ao processo de aprendizagem. Neste sentido, o computador tanto pode ser utilizado numa perspectiva de facilitar a compreensão do problema quanto de problematizar os conteúdos estudados. A perspectiva adotada nesta pesquisa propõe a problematização da tarefa, no sentido de desafiar o aluno, provocar nele a reflexão e a capacidade de desenvolver estratégias para solucionar problemas (LUCKIN, 2010).

No intuito de criar situações didáticas em que o recurso tecnológico fosse utilizado na perspectiva de problematizar os conteúdos, foi selecionado o aplicativo Squeak, disponível no laptop educacional presente em escolas participantes do Projeto Um Computador por Aluno (UCA) e teve como sujeitos participantes, estudantes de uma escola estadual do Município de Quixadá-Ceará, organizados em pares, que criaram desenhos e animações para representar conteúdos de Biologia do $3^{\circ}$ ano do Ensino Médio.

No decorrer deste trabalho discute-se a utilização das tecnologias digitais como suporte ao processo de ensino aprendizagem a partir de uma perspectiva colaborativa e tem como objetivo central:

- Analisar as interações que emergem do contexto da intervenção realizada e de que maneira interferem no processo de ensino aprendizagem dos conteúdos de Biologia estudados.

- Perceber as diversas formas de colaboração que surgiram das situações didáticas criadas durante a intervenção realizada na escola pesquisada.

O presente estudo está organizado nas seguintes sessões: introdução, com descrição breve do presente trabalho; método, que detalha os procedimentos metodológicos, necessários à realização da pesquisa; resultados alcançados e conclusões obtidas.

\section{Método}

O presente estudo optou por uma abordagem qualitativa, que tem caráter descritivo e explicativo e levou em conta não apenas dados numéricos, sobretudo os significados obtidos nas interações acontecidas entre os sujeitos participantes. Quanto ao envolvimento do pesquisador, caracteriza-se como uma pesquisa-intervenção, que segundo Damiani (2012), partem de uma intenção de mudança ou inovação, constituindo-se, em práticas a serem analisadas; trabalham com dados criados, em contraposição a dados já existentes, que são simplesmente coletados. 
V Congresso Brasileiro de Informática na Educação (CBIE 2016)

Anais dos Workshops do V Congresso Brasileiro de Informática na Educação (CBIE 2016)

A intervenção realizada na escola teve por pressuposto a criação de situações didáticas em que os estudantes foram incentivados a adotarem postura ativa e colaborativa na discussão e representação de problemas de ciências usando suporte das tecnologias digitais.

A proposta metodológica citada neste trabalho consistiu na utilização das seguintes estratégias didáticas:

$\checkmark$ Exposição dialogada do conteúdo pelo pesquisador (que assumiu o papel do professor);

$\checkmark$ Criação de animação, em pares de alunos, para representar o conteúdo de Biologia, através do aplicativo Squeak;

$\checkmark$ Apresentação das animações criadas pelos alunos para o professor e os colegas;

$\checkmark$ Intervenção do pesquisador através de perguntas, questionamentos, instigando a reflexão e a colaboração entre os pares.

Foram organizadas e realizadas 08 intervenções, abordando os seguintes conteúdos disciplinares de Biologia: fotossíntese, cadeia alimentar, fluxo de energia, ciclos biogeoquímicos: ciclo da água e do carbono, efeito estufa e poluição.

A escolha da ferramenta Squeak, utilizada na intervenção se deu em função das suas características: a possibilidade de criar objetos como desenho e animações e facilidade de uso, dentre as opções disponíveis.

O Squeak foi criado em 1996, por Alan Key e colaboradores no Viewpoints Research Institute, nos Estados Unidos. Inspirado nas ideias de Seymour Papert, este aplicativo tem como característica a possibilidade do aluno criar seus próprios objetos (desenhos e animações, por exemplo). Para Valente (201, p. 84), "o Squeak, é um IDE, ou sistema de programação orientado por objetos, inspirado no Logo". Tem como característica ser livre, de código aberto, baseado num modelo simples de criação de scripts voltados para manipulação dos objetos criados.

A pesquisa foi realizada numa escola situada em Quixadá, município do sertão central do Estado do Ceará. Situada numa área intermediária entre zona urbana e rural do referido município, atendendo a um público-alvo, que em grande parte provém da zona rural, com pouco acesso aos recursos tecnológicos digitais.

Os sujeitos da pesquisa foram 06 alunos do $3^{\circ}$ ano do Ensino Médio, selecionados a partir do critério de disponibilidade para participar das intervenções realizadas no contra turno.

Foram utilizadas duas técnicas de geração de dados:

a) Observação e registro em diário de campo: foram utilizados para acompanhar o trabalho nos grupos e verificar como se deu o processo de colaboração entre os pares e deste com os demais colegas. Foi observado também como os estudantes lidavam com a ferramenta utilizada e os conteúdos de Biologia escolhidos.

b) Registro em áudio e vídeo: buscou registrar o trabalho no interior dos grupos e nos momentos de socialização das animações. Foi um instrumento complementar às observações do pesquisador e permitiu analisar de forma minuciosa as interações estabelecidas entre os participantes e destes com os conteúdos disciplinares e a ferramenta escolhida. 
V Congresso Brasileiro de Informática na Educação (CBIE 2016)

Anais dos Workshops do V Congresso Brasileiro de Informática na Educação (CBIE 2016)

Os diversos dados coletados foram confrontados com referencial teórico adotado gerando as reflexões que serão apresentadas na sessão a seguir.

\section{Resultados}

Os resultados do presente trabalho estão organizados em torno das contribuições aos processos de ensino e de aprendizagem, através da mediação do suporte das tecnologias digitais.

A utilização das TIC numa perspectiva que dá suporte a criação coletiva abre espaço para a superação do modelo de simples memorização de conceitos, aplicação de técnicas repetitivas e transmissão de conteúdos. Os excertos apresentados neste trabalho evidenciam que a utilização da ferramenta Squeak a partir de uma proposta metodológica baseada na colaboração proporcionou mudanças nas posturas docentes e discentes.

A abordagem utilizada neste trabalho buscou problematizar os conteúdos estudados através da formulação de desafios que foram solucionados de maneira colaborativa. Os pares produziram desenhos, utilizaram scripts para atribuir movimento aos objetos criados, além aplicar diversos outros recursos disponíveis no software.

Em situações, como a descrita anteriormente, em que o suporte oferecido pelos recursos computacionais teve a função de problematizar os conteúdos estudados, a mediação do professor mostrou-se de grande relevância. Tal fato foi observado durante a pesquisa, nas diversas situações didáticas que necessitavam da habilidade para solucionar problemas.

Luckin (2010) destaca que quando se trata de oferecer ao aluno uma situação desafiadora o feedback oferecido pelo professor terá papel de grande relevância, pois caberá a ele identificar o nível de complexidade da tarefa e ajustá-la às possibilidades dos estudantes. Trata-se de definir o nível de assistência necessário que esteja mais próximo às necessidades dos estudantes.

A atuação do mais experiente na aquisição de novos saberes tem grande destaque nas formulações de Vygotsky (2007). No contexto de sala de aula esse papel pode ser desempenhado tanto pelo professor, quanto por colegas, que num determinado momento, tenham adquirido maior conhecimento a respeito de uma temática específica. Neste trabalho, observa-se, tanto as interações entre alunos, quanto a atuação do professor como mediador.

Como será visto adiante, as possibilidades educacionais da ferramenta escolhida foram potencializadas pela mediação do professor que interviu de diversas formas. A problematização da tarefa foi realizada no sentido de desafiar o aluno, provocar nele a reflexão e a capacidade de desenvolver estratégias para solucionar problemas (LUCKIN, 2010).

A atuação docente, assumida pelo pesquisador, utilizou diferentes estratégias didáticas, desde a contextualização e explicitação dos vínculos entre os diversos saberes até perguntas que incitaram a reflexão. Na situação apresentada a seguir (excerto 01), a mediação se deu principalmente através da formulação de perguntas. O professor 
V Congresso Brasileiro de Informática na Educação (CBIE 2016)

Anais dos Workshops do V Congresso Brasileiro de Informática na Educação (CBIE 2016)

desafiou os estudantes através de proposição de questionamentos, instigando-os à reflexão.

Excerto 01: O vídeo transcrito foi coletado na $3^{\mathrm{a}}$ aplicação da pesquisa. Nele consta o registro do momento em que os pares planejam a criação de uma animação para representar a cadeia alimentar. Retrata o momento em que as alunas discutem sobre qual direção as setas devem indicar e revela os diferentes posicionamentos que possuem a respeito da temática em estudo.

1 - P: Porque você acha que deve ser assim, aluna C?

2 - Aluna M1: não é o gafanhoto que come a planta, o sabiá o gafanhoto, a cobra o sabiá... então porque que a seta é assim?

3 - P: por que você acha que é dessa forma, Aluna C?

4 - (Aluna $\mathrm{C}$ indica a ordem da cadeia alimentar)

5 - P: e você, aluna M1, pensa diferente?

6 - (Aluna M1 diz que a direção das setas que indicam a orientação da cadeia alimentar deveria ser diferente)

7 - (Alunas permanecem em dúvida quanto a essa questão)

8 - P: o que essa cadeia indica? o que vocês estão representando nessa cadeia?

10 - Aluna M1: os consumidores?

11 - P: Quem são os consumidores?

12 - (Alunas indicam, no desenho criado, os consumidores primário, secundário, terciário e quaternário, além do produtor)

13 - P: e a questão do fluxo de energia?

14 - (Aluna M1 indica, no desenho criado, em que direção se dá o fluxo de energia)

15 - P: ela vai aumentando ou diminuindo ao longo da cadeia?

Aluna M1: diminui.

16 - P: porque?

17 - Aluna M1: porque não tem como ficar com a mesma energia. Eles liberam.

18 - Aluna C: na forma de calor.

19 - P: que vai se perdendo, é isso?

20 - (Alunas concordam)

21 - P: mas porque que se perde?

22 - Aluna M1: porque ele vai pular de um galho para outro... (risos)

23 - P: e quem tem mais energia?

24 - Aluna M1: a planta.

25 - P: e depois da planta?

26 - Aluna M1: o gafanhoto.

As interações mostradas anteriormente reiteram a importância e o caráter indispensável da atuação docente, no sentido de criar ambientes que possibilitassem o surgimento de interações capazes de instigar a criatividade, colaboração e capacidade de resolução de problemas. Tais situações proporcionaram o devido envolvimento com os conteúdos estudados e, a partir dele, ampliaram-se as possibilidades de aprendizado (D'AVILA, 2008; MASSETO, 2003; TORRES e IRALA, 2007).

Ao utilizar a ferramenta Squeak para representar conteúdos estudados os estudantes foram postos diante de diversas dificuldades. Desde as operacionais, referentes à utilização dos recursos disponíveis no aplicativo até as mais desafiadoras, como se mostrou a tarefa de usar conhecimentos de Biologia para resolver problemas. A proposta lançada aos estudantes os colocou diante da necessidade mobilizar saberes e 
V Congresso Brasileiro de Informática na Educação (CBIE 2016)

Anais dos Workshops do V Congresso Brasileiro de Informática na Educação (CBIE 2016)

habilidades, um obstáculo considerável aos conhecimentos que eles dispunham. Através das diversas formas de colaboração estabelecidas foi possível superar obstáculos e produzir como a que

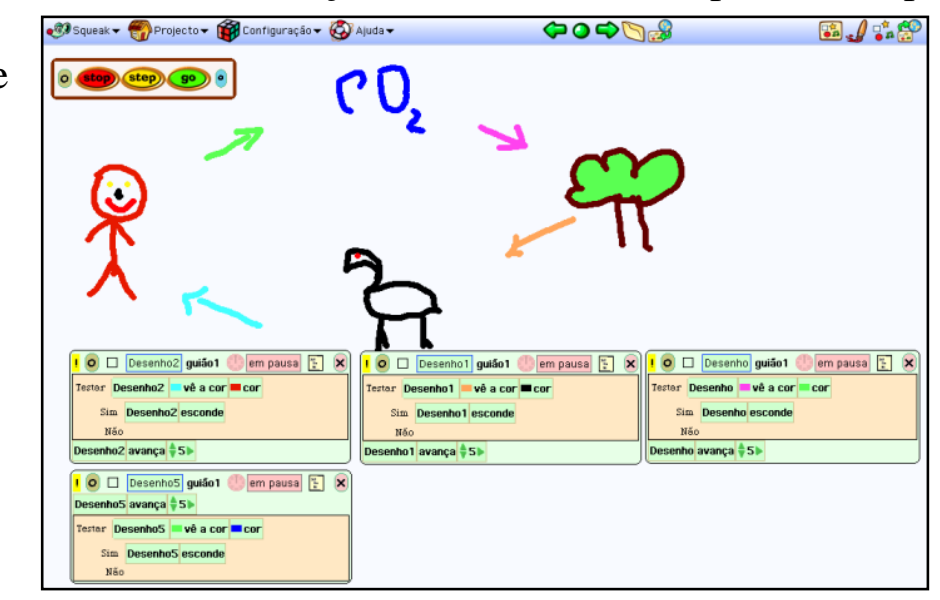
animações representada seguir: na figura 01 , a

\section{Figura 01: animação criada para representar o ciclo do carbono, contendo os recursos utilizados.}

Numa situação em que pares de estudantes utilizam-se de simulações de fenômenos da natureza, como o ciclo do carbono, por exemplo, o que é visualizado na tela do computador pode funcionar como uma representação do real, apoiando a negociação de significados e a mediação da comunicação entre os estudantes, facilitando a compreensão recíproca (LIPPONEN, 2002).

Luckin (2010) ressalta a interação com os pares a partir da ideia de andaimes, que dão suporte ao entendimento dos participantes nos momentos de interação. $\mathrm{O}$ excerto 02 também mostra indícios que a troca de ideias entre os pares e as intervenções realizadas pelo pesquisador serviram para dar suporte à formulação de novas compreensões o que confirma as formulações da autora quanto à ideia dos andaimes, como será visto a seguir:

Excerto 02: O vídeo transcrito foi coletado na $8^{\mathrm{a}}$ aplicação da pesquisa. Nele consta o registro do momento registro do momento em que os alunos planejam a realização da atividade.

1- Questionados sobre como fariam a animação proposta pelo $\mathrm{P}$, os alunos responderam:

2 - Aluna L: a gente vai apresentar o que a gente aprendeu, só que no Squeak... a gente encontra muito do dia-a-dia a poluição nos rios... aí eu queria demonstrar.

3 - P: que conteúdos você relaciona com a poluição dos rios, do que vocês estudaram até aqui?

4 - Aluno J: o meu dá pra relacionar porque eu fiz da eu fiz a poluição dos combustíveis fósseis, dos veículos, aí da pra relacionar com os gases do efeito estufa.

5 - P: e a animação que vocês pretendem criar no Squeak, de que forma ela se relaciona com o que a gente estudou nesse tempo aqui?

6 - Aluna L: ... um conteúdo que eu achei muito interessante foi o ciclo da água... quando chove não forma o rio?! Nesse rio, poderíamos aproveitar de outra forma, não jogando lixo. 
V Congresso Brasileiro de Informática na Educação (CBIE 2016)

Anais dos Workshops do V Congresso Brasileiro de Informática na Educação (CBIE 2016)

7 - P: Tô entendendo, a questão da poluição dos rios com o ciclo da água, não é?! Mas aí, eu teria uma pergunta a fazer... nós estudamos a cadeia alimentar, não foi?! Será que ela se relaciona de alguma forma com a poluição dos rios? 8 - Alunos permanecem pensativos...

9 - P: de que forma a poluição dos rios interfere na cadeia alimentar?

10 - Aluna L: ahhh... (expressão de admiração) com o derramamento de petróleo no rio, os peixes vão morrer, eu pensei desta forma.

11 - P: to acompanhando o seu raciocínio... e como ela interfere mais?

12 - Aluno J: interfere na... se matar ... me ajuda aluna L... se matar um certo tipo de peixe, o que se alimenta dele também vai entrar em extinção.

13 - Justamente, aluno J! Comemora, a aluna L.

De acordo com Colaço (2007), a escola é um espaço singular para a construção do conhecimento científico, entretanto é necessário organizar as situações didáticas de maneira a favorecer a construção destes saberes, que se dá principalmente a partir de atividades compartilhadas e da possibilidade efetiva de trocas.

Confirmando as ideias anteriores, Silva, Pimentel e Dias (2015) afirmam que a aprendizagem colaborativa atende as necessidades da sociedade atual, baseada nas conexões em rede, no trabalho colaborativo e na autonomia dos participantes. A escola dos tempos atuais precisa incorporar esse novo paradigma, provendo a participação ativa dos estudantes, a coautoria e colaboração.

A proposta metodológica adotada neste trabalho favoreceu o surgimento de interações entre os estudantes. $\mathrm{O}$ fato dos estudantes terem sido provocados a criar, ao invés de apenas assistirem aulas expositivas se constituiu numa mudança de paradigma que trouxe uma série de benefícios, como serão relatados a seguir.

Pozo (2009) destaca que compreender é identificar as relações entre diversos saberes. É situá-los dentro de uma rede de significados. Uma pessoa adquire um conceito quando é capaz de dotar de significado uma informação que lhe é repassada. $\mathrm{Na}$ sequência apresentada a seguir, observa-se que durante os estudos do conteúdo Poluição os estudantes identificaram as relações entre este conteúdo e outros estudados anteriormente, como se ver no excerto 03 , a seguir.

Excerto 03: $O$ vídeo transcrito foi coletado na $8^{\text {a }}$ aplicação da pesquisa. Nele consta o registro do momento da socialização do desenho criado, por um dos pares, para representar diferentes tipos de poluição.

1 - Aluna M: “A fábrica joga... (ALUNA C: dejetos) dejetos no rio, matando os animais, diminuindo a comida das aves e também soltando gases poluentes no ar, aumentando o efeito estufa assim, o efeito estufa".

2 - P: Um exemplo desses gases poluentes...

3 - Aluna M: CO2?

4 - P: $\mathrm{CO} 2$

5 - P: certo, continuem... o que mais vocês tem a falar?

6 - (a afirmação a seguir é feita indicando o desenho criado no laptop)

7 - aluna M: com o esgoto jogado nos rios mata os animais, os peixes e o microoganismos, diminuindo a cadeia alimentar das aves. Né?!

8 - (a afirmação a seguir é feita indicando o desenho criado no laptop)

9 - aluna M: polui o ar, sendo assim aumentando o calor da terra.

10 - Aluna C: o efeito estufa prejudica muito a atmosfera e o...

(trecho imcompreensivel)

Por causa do efeito estufa, a temperatura ta se elevando muito por causa dos gases que a fábrica solta, por causa dos combustíveis fósseis que são 
V Congresso Brasileiro de Informática na Educação (CBIE 2016)

Anais dos Workshops do V Congresso Brasileiro de Informática na Educação (CBIE 2016)

queimados, negócio de carro, essas coisas... por causa das queimadas. Por causa disso o ar... a temperatura vai se elevando muito... uma consequência disso é que as geleiras... a temperatura ta tão quente que elas tão derretendo e aumentando o nível do mar. Daqui uns dias, vai tomar as terras tudim e nós vamos morrer afogados (risos)".

11 - P: o efeito estufa em si, ele prejudica? Ou pode ser positivo também? Ele tem algum benefício?

12 - Aluno J: o efeito estufa ele é benéfico, agora com a ação do homem ta tornando... (aluna L, completa: "maléfico").

13 - P: Porque? Como ele pode se tornar maléfico?

14 - Aluno J: o gás que é liberado do sol não volta"

15 - P: a radiação solar né?!

16 - P: E não volta porque?

17 - Aluno J: Por causa da acumulação de gases que está muito grande.

18 - P: o que mais vocês tem a acrescentar? Dos conteúdos que nós estudamos até agora, quais foram os que vocês identificaram que estão relacionados com o desenho ou animação de vocês?

19 - Aluna M: o efeito estufa, a cadeia alimentar.

20 - P: Porque a cadeia alimentar se relaciona com o que vocês criaram?

21 - (a afirmação a seguir é feita indicando o desenho criado no laptop)

22- Aluna C: por causa da poluição dos rios tá matando os peixes... aí aves que se alimentam dos peixes, como os peixes vão morrer, elas não vão ter do que se alimentar... vão ficar com fome e vão morrer também.

23 - Aluno J: entendi o raciocínio da aluna $\mathrm{C}$ agora, é porque tem aqueles pássaros que se alimentam dos próprios peixes. Com a extinção dos peixes, há a extinção dos pássaros também.

O conteúdo poluição é relacionado ao conteúdo cadeia alimentar, estudado anteriormente. $\mathrm{Na}$ oportunidade os estudantes observaram que as consequiências da poluição interferem na cadeia alimentar, ocasionando a morte de alguns dos seus elementos e por consequência afeta dos diversos níveis tróficos e seus componentes.

Outro conteúdo relacionado à poluição foi o efeito estufa. Das interações realizadas entre os estudantes chegou-se à conclusão que o aumento da presença de gases na atmosfera ocasionado pela queima das árvores e da emissão de gases das indústrias intensifica o efeito estufa e este por sua vez, provoca a elevação do clima no planeta.

Os excertos apresentados, mostram ampliação nas participações e que as situações colaborativas ampliam a verbalização das ideias. Este fato ganha importância a partir das formulações de Vygotsky (2007) a respeito da linguagem enquanto mediadora dos processos de desenvolvimento das funções psicológicas superiores. As diversas falas apresentadas mostram que houve regulação mútua do pensamento e que, da expressão dos diversos pensamentos, surgiu troca de entendimentos, que influenciou o pensamento de ambos os participantes a respeito das questões tratadas.

De acordo com Lipponen (2012), as tecnologias digitais podem ser o meio para explicitar o pensamento dos estudantes. Ao torná-lo visível a si e aos outros, cria-se a possibilidade de refletir sobre suas próprias ideias e compartilhar com os outros. Em situações colaborativas as ideias individuais ganham uma dimensão coletiva, a partir das discussões que se estabelecem.

Da capacidade de interagir entre si e da intervenção realizada pelo pesquisador os estudantes conseguiram contextualizar os diversos conteúdos estudados. Nesta 
situação os saberes da ciência passaram a ter significado para eles e as dificuldades de entendimento e envolvimento foram minimizadas, o que mostra a estratégias adotadas tiveram impacto positivo nos processos de ensino e aprendizagem dos alunos participantes.

Todas as contribuições relatadas neste trabalho evidenciam a relevância da pesquisa realizada.

\section{Conclusões}

A atuação docente foi decisiva diante da necessidade inicial de romper com o desinteresse pelo estudo das ciências. Nem mesmo a ferramenta tecnológica com seus atrativos por si só garante o encantamento pela Biologia. $\mathrm{O}$ envolvimento esperado foi surgindo na medida em que os estudantes foram se apropriando dos saberes que estavam envolvidos nas atividades. Neste sentido a atuação insistente e mediadora docente promoveu as aproximações necessárias e o despertar do gosto por esta importante área de saber.

Dentre as contribuições da ferramenta Squeak ressalta-se o fato desta proporcionar aos estudantes a criação dos objetos, como os desenhos e animações. Este fato mudou a relação dos estudantes com o objeto de estudo e com o pesquisador, que na ocasião também atuou como docente. $\mathrm{O}$ acompanhamento do processo de criação e depois de socialização das produções foram momentos ricos de trocas de entendimentos e dúvidas entre os estudantes, além da intervenção docente.

Neste estudo a utilização de uma tecnologia digital que permite criar, recriar, incorporar objetos de outros contextos viabiliza a expressão do pensamento e a partir dela, o confronto de ideias e as trocas tão relevantes à aquisição de novos saberes. Neste sentido a perspectiva individual cedeu lugar à atuação coletiva, em os pares interagem na busca de elaborar conhecimentos comuns.

O suporte oferecido pelo instrumento teve como pressuposto a ideia de que o aprendizado se dá a partir das interações como os membros mais experientes e com os instrumentos do meio cultural. Desta forma é preciso considerar que orientação metodológica de quem organiza a ação docente, esteja ela implícita ou não, esteja utilizando tecnologias digitais ou não, é determinante para atingir os resultados educacionais almejados.

\section{Referências}

BRASIL (2002). Secretaria da Educação Média e Tecnológica. PCN + Ensino Médio: Orientações Educacionais complementares aos Parâmetros Curriculares Nacionais. Brasília: MEC/SEMTEC.

BERENS, M. A. (2007) . Projetos de Aprendizagem Colaborativa num Paradigma Emergente In: MORAN, José Manuel. Novas Tecnologias e Mediação Pedagógica. Campinas, SP: Papirus.

COLAÇO, V. et Al. (2007). Estratégias de mediação em situação de interação entre crianças em sala de aula. Estud. psicol. (Natal) [online]. vol.12, n.1, pp. 47-56. ISSN 1413-294X. http://dx.doi.org/10.1590/S1413-294X2007000100006. 
V Congresso Brasileiro de Informática na Educação (CBIE 2016)

Anais dos Workshops do V Congresso Brasileiro de Informática na Educação (CBIE 2016)

COLL, C. Psicologia da Educação Virtual: aprender e ensinar com as tecnologias da informação e comunicação. Porto Alegre: Artmed, 2010.

DAMIANI, M. (2012). Sobre pesquisas do tipo intervenção. XVI Encontro Nacional de Didática e Práticas de Ensino (ENDIPE). Campinas.

D'ÁVILA, Cristina Maria. Decifra-me ou te devorarei: o que pode o professor frente ao livro didático? Salvador: EDUNEB; EDUFBA, 2008.

KENSKI, V. M. (2007). Educação e Tecnologias: o novo ritmo da informação. Campinas: Papirus.

LUCKIN, R. Re-designig Learning Contexts. New York. 2010.

LIPPONEN L. (2002). Exploring foundations for computersupported collaborative learning. CSCL 2002. Colorado Boulder. USA.

MASSETO, M. Mediação Pedagógica e o Uso da Tecnologia In: MORAN, José Manuel. Novas Tecnologias e Mediação Pedagógica. Campinas, SP: Papirus, 2000.

PAPERT, S. (2008). A máquina das crianças: repensando a escola na era da informática. Porto Alegre: Artmed.

POZO, J. (2009). A aprendizagem e o ensino de ciências: do conhecimento cotidiano ao conhecimento científico. Porto Alegre: Artmed.

SAVIANI, D. (2010). História das Ideias Pedagógicas no Brasil. $3^{\mathrm{a}}$ ed. Campinas, SP, Autores Associados.

SILVA, V.; PIMENTEL, M.; DIAS, V. (2015). Bate-papo Colaborativo ou Centrado no Professor? . SIMPÓSIO BRASILEIRO DE INFORMÁTICA NA EDUCAÇÃO. 26, Alagoas. Anais.... p. 1303 - 1312.

STAHL, G.; KOSCHMANN, T. ; SUTHERS, D. Aprendizagem colaborativa com suporte computacional: Uma perspectiva histórica - Traduzido por: Hugo Fuks, Tatiana Escovedo (Português do Brasil), 2006.

TORRES, P. L. (2007). Algumas vias para entender o pensar e o agir. Curitiba: SENAR-PR.

Valente, L., \& Osório, A. J. (2011). Integração das TIC na educação:o caso do Squeak Etoys. Tese (Doutorado em Estudos da Criança). Universidade do Minho. Brga, Portugal.

VYGOTSKY. L. S. (2007) A formação social da mente: o desenvolvimento dos processos psicológicos superiores. $7^{\mathrm{a}}$ ed. São Paulo: Martins Fontes. 